\title{
Prostacyclin Production by the Deendothelialized Rabbit Aorta
}

\author{
J. M. Boeynaems, N. Galand, and P. Ketelbant \\ Institute of Interdisciplinary Research and Department of Pathology of Erasme Hospital, Université Libre de Bruxelles, \\ Brussels, Belgium
}

\begin{abstract}
The acute effect of in vitro deendothelialization on the production of prostacyclin (PGI $)$ by the rabbit aorta has been investigated. The effectiveness of removing endothelium by rubbing it against filter paper or scraping it with a scalpel was demonstrated by scanning electron microscopy and en face examination after silver staining. Endothelium removal produced an immediate stimulation of $\mathrm{PGI}_{2}$ release, resulting in $408 \%$ of the control after rubbing and $367 \%$ of the control after scraping, during the first 30-min period of incubation. This increased production of PGI $_{2}$ gradually declined over time to reach values similar to the control after $2 \mathrm{~h}$. At that time, the deendothelialized aorta was totally unresponsive to the stimuli that increase $\mathbf{P G I}_{2}$ release in the intact aorta (acetylcholine, ADP, ionophore A23187, and arachidonic acid). The enhanced production of $\mathbf{P G I}_{2}$ in the deendothelialized aorta was associated with an increased release of free arachidonic acid (353\% of the control): in contrast with $\mathbf{P G I}$, this stimulation was maintained for at least 150 min. A transient exposure of the deendothelialized aorta to ibuprofen $(250 \mu \mathrm{M})$ was followed by a rebound of PGI $_{2}$ production, which was also prolonged by BW-755C (3$10 \mu \mathrm{M})$. In conclusion, removal of the endothelium triggered an immediate and sustained mobilization of free arachidonic

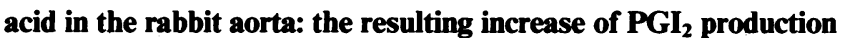
was short-lived, probably as a consequence of cyclooxygenase self-inactivation. Our results indicate that the subendothelium has a significant capacity to produce $\mathbf{P G I}_{2}$, but that this capacity is expressed only briefly.
\end{abstract}

\section{Introduction}

The relative contribution of the endothelium and the subendothelium to the production of prostacyclin $\left(\mathrm{PGI}_{2}\right)^{1}$ by arteries remains a controversial matter. $\mathbf{P G I}_{2}$ is the major eicosanoid produced by cultured smooth muscle cells from rat (1), rabbit $(2,3)$, and bovine (4-6) aorta, whereas smooth muscle cells from porcine aorta synthesize mainly prostaglandins $\mathrm{E}_{2}\left(\mathrm{PGE}_{2}\right)$ and $F_{2 \alpha}\left(P F_{2 \alpha}\right)(7-9)$. After in vivo deendothelialization, the release of $\mathrm{PGI}_{2}$ at the luminal surface of the rabbit aorta, induced by arachidonic acid, is abolished (10); removal of the

Address reprint requests to Dr. Boeynaems, Bldg. C, Campus Erasme, 808 Route de Lennik, 1070 Bruxelles, Belgium.

Received for publication 8 March 1984 and in revised form 26 February 1985.

1. Abbreviations used in this paper: ECD, electron capture detection; GLC, gas liquid chromatography; 6-K-PGF ${ }_{1 \alpha}$, prostaglandin-6-keto$\mathrm{F}_{1 \alpha} ; \mathrm{PGE}_{2}$, prostaglandin $\mathrm{E}_{2} ; \mathrm{PGF}_{2 \alpha}$, prostaglandin $\mathrm{F}_{2 \alpha} ; \mathrm{PGI}_{2}$, prostacyclin; RPHPLC, reversed-phase high performance liquid chromatography.

J. Clin. Invest.

(c) The American Society for Clinical Investigation, Inc.

0021-9738/85/07/0007/08 $\$ 1.00$

Volume 76 , July $1985,7-14$ endothelium inhibits the capacity of dog femoral arteries to convert exogenous arachidonic acid into $\mathrm{PGI}_{2}$ (11). Immunoradiometric assays and immunofluorescence studies have shown that the concentrations of $\mathrm{PGI}_{2}$ synthase are equal in endothelial and smooth muscle cells of bovine aorta, but that the concentration of cyclooxygenase is 20 -fold higher in the endothelial than in the smooth muscle cells $(12,13)$. We have performed a detailed kinetic study of the consequences of in vitro deendothelialization on arachidonic acid release and $\mathrm{PGI}_{2}$ production in the rabbit aorta. Our results indicate that removal of the endothelium induces a sustained mobilization of free arachidonic acid and a transient stimulation of $\mathrm{PGI}_{2}$ release: the subendothelium has a significant capacity to produce $\mathrm{PGI}_{2}$, but, due to cyclooxygenase self-inactivation, the expression of this capacity is short-lived.

\section{Methods}

Preparation and incubation of aortic strips. White male rabbits weighing $\sim 3 \mathrm{~kg}$ were killed by a blow on the neck. The aorta was quickly dissected from the iliac bifurcation up to the arch, trimmed free of fat and connective tissue, and cut into rings ( $\pm 3 \mathrm{~mm}$ large). These rings were opened by a longitudinal incision, and the intimal face of some of the resulting strips was either rubbed for $30 \mathrm{~s}$ against filter paper or scraped with a scalpel. Immediately thereafter, the strips were incubated at $37^{\circ} \mathrm{C}$, under constant shaking $(80 \mathrm{rpm})$, in a medium of the following composition: $124 \mathrm{mM} \mathrm{NaCl} ; 5 \mathrm{mM} \mathrm{KCl} ; 1.25 \mathrm{mM} \mathrm{MgSO}_{4}$; $1.45 \mathrm{mM} \mathrm{CaCl}_{2} ; 1.25 \mathrm{mM} \mathrm{KH} \mathrm{PO}_{4} ; 25 \mathrm{mM}$ Hepes buffer, $\mathrm{pH}$ 7.4; and $8 \mathrm{mM}$ glucose. The ratio of tissue weight to medium volume was roughly $25 \mathrm{mg} / 2 \mathrm{ml}$. In general the strips were incubated for five 30 min periods (60 min in some experiments), and the medium was replaced at the end of each period. For the measurement of arachidonic acid release, the same medium was used, but it contained in addition indomethacin $(1 \mu \mathrm{g} / \mathrm{ml})$ and bovine serum albumin (BSA; $1 \mathrm{mg} / \mathrm{ml})$. In some experiments, the strips of rabbit aorta were placed between two plexiglass plates held together by two lateral screws. The upper plate, the base of which was constituted by the aortic luminal surface, contained six holes $(5 \mathrm{~mm})$ that served as incubation chambers. The chambers were filled with $300-\mu l$ incubation medium and incubated at $37^{\circ} \mathrm{C}$ for six $30-\mathrm{min}$ periods. At the end of each period, the incubation medium was collected and replaced. Within an experiment (performed with one aorta), each experimental condition was tested in duplicate or triplicate.

Prostaglandin radioimmunoassay (RIA). The production of $\mathrm{PGI}_{2}$ was measured by the RIA of prostaglandin-6-keto- $F_{1 \alpha}\left(6-K-P G F_{1 \alpha}\right)$, performed directly in the incubation medium without extraction and chromatography. A rabbit antiserum was raised against 6-K-PGF ${ }_{1 \alpha}$ coupled to BSA, as described (14): the limit of detection was $16 \mathrm{pg}$ and the cross-reactions were $1.2 \%$ with $\mathrm{PGF}_{2 \alpha}, 0.3 \%$ with $\mathrm{PGE}_{2}$, and $<0.1 \%$ with thromboxane $B_{2}$. 20- or $50-\mu 1$ aliquots of incubation media, ${ }^{3} \mathrm{H}-6-\mathrm{K}-\mathrm{PGF}_{1 \alpha}\left(11,000 \mathrm{dpm}\right.$ ), anti-6-K-PGF ${ }_{1 \alpha}$ antiserum (final dilution, $\left.10^{-4}\right)$, and bovine gamma globulins $(0.25 \%)$ in Tris buffer $(50$ $\mathrm{mM}, \mathrm{pH}$ 7.4) were incubated in a total volume of $0.4 \mathrm{ml}$ for $60 \mathrm{~min}$ at room temperature. Then $0.4 \mathrm{ml}$ of a cold $25 \%(\mathrm{wt} / \mathrm{wt})$ solution of polyethylene glycol was added to separate bound and free antigen. $\mathrm{PGE}_{2}$ was assayed by a similar method.

Metabolism of exogenous arachidonic acid. Intact and rubbed strips of rabbit aorta $( \pm 50 \mathrm{mg})$ were incubated for four 30 -min periods, in $2 \mathrm{ml}$ of the usual medium. $\left[{ }^{3} \mathrm{H}\right]$ Arachidonic acid $(135 \mathrm{Ci} / \mathrm{mmol})$, 
purified shortly before use, was added at the beginning of the fourth period $(1 \mu \mathrm{Ci} / \mathrm{ml}, 0.25 \mu \mathrm{g} / \mathrm{ml})$. A $1.5-\mathrm{ml}$ aliquot of the incubation medium was directly analyzed by reversed-phase high performance liquid chromatography (RPHPLC), using a $\mu$-Bondapak $\mathrm{C}_{18}$ column $(3.9 \times 300 \mathrm{~min}, 10 \mu \mathrm{m}$ particles; Waters Associates, Millipore Corp., Milford, MA). The injector (model U6K), the pumps (model $6000 \mathrm{~A}$ ), and the gradient programmer (model 600 ) were also from Waters Associates, Millipore Corp. Elution was performed with a mixture of acetonitrile/water/acetic acid (26:74:0.08; vol/vol) at a flow rate of 2 $\mathrm{ml} / \mathrm{min}$ for $30 \mathrm{~min}$. Then a linear gradient from this initial composition to acetonitrile/acetic acid (100:0.01; vol/vol) was developed in $37 \mathrm{~min}$ ( $2 \mathrm{ml} / \mathrm{min}$ ). 2-ml fractions were collected and counted by liquid scintillation.

Assay of free arachidonic acid release. Arachidonic acid was measured by gas liquid chromatography (GLC) with electron capture detection (ECD). Aortic strip incubations were performed in a medium containing BSA $(1 \mathrm{mg} / \mathrm{ml})$ and indomethacin $(1 \mu \mathrm{g} / \mathrm{ml})$. After the addition of $1 \mu \mathrm{g}$ docosahexaenoic acid as an internal standard, the incubation medium was extracted with 1 vol ethyl acetate. The FFA were converted into pentafluorobenzyl esters by a modification of the method of Wickramasinghe et al. (15). To the dry residue of the extract were added $290 \mu \mathrm{g}$ pentafluorobenzylbromide (in $5 \mu$ l acetonitrile) and $44 \mu \mathrm{g}$ diisopropylethylamine (in $5 \mu \mathrm{l}$ acetonitrile). After 5 min at $40^{\circ} \mathrm{C}$ and evaporation of the solvent under nitrogen, the samples were redissolved in $50 \mu \mathrm{l}$ hexane. The 20 -fold reduction in the amounts of reagents used, as compared with the original procedure, made it possible to directly analyze the samples without prior purification. The aorta strips did not release significant amounts of endogenous docosahexaenoic acid. GLC analysis was performed in a Varian instrument (model 3700; Varian Associates, Palo Alto, CA) equipped with a ${ }^{63} \mathrm{Ni}$ ECD. 2-m columns of $3 \%$ OV-1 on Gas chrom Q (Applied Science Laboratories, Div. of A. S. Laboratories, Inc., Waltham, MA) were used isothermally at $235^{\circ} \mathrm{C}$.

Morphological examinations. The effectiveness of endothelium removal was checked by en face microscopic examination after silver staining (16). Aortic strips were immersed for 1-min periods in the dark at room temperature sequentially in $5 \%$ glucose, $0.25 \% \mathrm{AgNO}_{3}$, $5 \%$ glucose, $3 \% \mathrm{CoBr}_{2}+1 \% \mathrm{NH}_{4} \mathrm{Br}$, and $5 \%$ glucose (twice). Deendothelialization was also checked by scanning electron microscopy (17). Rabbit aorta strips were fixed in $4 \%$ glutaraldehyde in $0.1 \mathrm{M}$ phosphate buffer, $\mathrm{pH} 7.4$, at room temperature, washed in the same buffer, postfixed in $1 \%$ osmium tetroxide, dehydrated in acetone, processed through the critical point, and finally coated with gold. They were examined with an electron microscope $(80 \mathrm{kV}$, model EM 400; Philips Electronic Instruments, Inc., Mahwah, NJ).

Statistical analysis. The statistical significance of observed differences was established using the analysis of variance for repeated measurements with two within factors (time period and treatment) and one grouping factor (animal). Computerizations were performed with the use of the $\mathrm{P}_{2} \mathrm{~V}$ program of the BMDP statistical software (18).

Materials. Arachidonic and docosahexaenoic acids were purchased from Sigma Chemical Co., St. Louis, MO. Ionophore A23187 was obtained from Boehringer Mannheim Diagnostics, Inc., Mannheim, FRG. BSA (fatty acid poor) was purchased from Calbiochem-Behring Corp., La Jolla, CA. Indomethacin, ibuprofen, and BW-755C were gifts from Merck Sharp \& Dohme Div., West Point, PA, Upjohn Co., Kalamazoo, MI, and The Wellcome Foundation, Ltd., The Wellcome Research Laboratories, Beckenham, Kent, England, respectively. 6-K$\mathrm{PGF}_{1 \alpha}$ and $\mathrm{PGE}_{2}$ were purchased from Upjohn Co.; $\left.{ }^{3} \mathrm{H}\right] 6-\mathrm{K}-\mathrm{PGF}_{1 \alpha}$, $\left[{ }^{3} \mathrm{H}\right] \mathrm{PGE}_{2}$, and $\left[{ }^{3} \mathrm{H}\right]$ arachidonic acid were from Amersham Corp., Amersham, England. The antiserum against $\mathrm{PGE}_{2}$ was obtained from Institut Pasteur de Paris, France. $\mathrm{PGH}_{2}$ synthase, purified to homogeneity from ram seminal vesicles, was purchased from Oxford Biomedical Research, Oxford, MI. Acetonitrile, pentafluorobenzylbromide, and diisopropylethylamine were purchased respectively from Burdick \& Jackson Laboratories, Inc., American Hospital Supply Corp., Muskegon, MI, Pierce Chemical Co., Rockford, IL, and Sigma Chemical Co.

\section{Results}

The endothelium was completely removed from the rabbit aorta strips after their luminal surfaces were rubbed against filter paper or scraped with a scalpel. The en face examination of the complete surfaces of numerous scraped strips, after silver staining, revealed the homogenous loss of the mosaic pattern characteristic of the endothelium (16). Scanning electron microscopy provided similar results. Endothelium removal induced a transient increase of $6-\mathrm{K}_{-}-\mathrm{PGF}_{1 \alpha}$ release from the rabbit aorta strips (Fig. 1). The amounts of 6-K-PGF (nano- $_{1 \alpha}$ grams per 100 milligrams of tissue) released by the strips during the first 30 -min incubation period after their preparation were for the intact, rubbed, and scraped strips, respectively, $67 \pm 8(n=23), 248 \pm 26(n=14)$, and $219 \pm 19 \quad(n=23)$ (mean \pm SE; $n$, number of experiments). Rubbing and scraping produced an equal stimulation of $6-\mathrm{K}_{-}-\mathrm{PGF}_{1 \alpha}$ output of $408 \%$ of the respective controls in the case of rubbing and $367 \%$ in the case of scraping. To confirm that the product formed after endothelium removal was authentic 6-K-PGF $1 \alpha$, RIA was repeated after RPHPLC purification of several samples. All the immunoreactivity was indeed recovered in the fractions where a standard of 6-K-PGF ${ }_{1 \alpha}$ was eluted (data not shown). Scraping the endothelium of the dog aorta also stimulated the release of $6-\mathrm{K}_{-} \mathrm{PGF}_{1 \alpha}(270 \%$ of the control, mean of three experiments). The increased production of 6-K-PGF ${ }_{1 \alpha}$ in the deendothelialized aorta progressively declined with time, both when the strips were incubated continuously in the same medium (Fig. 1) and when the medium was changed every 30 min (Fig. 4). Indomethacin abolished the release of 6-K-PGF $F_{1 \alpha}$ induced by deendothelialization (Fig. 2). Endothelium removal also increased the release of $\mathrm{PGE}_{2}$ by rabbit aorta strips but in smaller amounts $(32 \mathrm{ng} / 100 \mathrm{mg}$ during the first $30 \mathrm{~min}$, or nine times less than the corresponding amounts of $6-\mathrm{K}_{-} \mathrm{PGF}_{1 \alpha}$; mean of four experiments). $\mathrm{PGE}_{2}$ output decreased with time parallel to 6-K-PGF ${ }_{1 \alpha}$ (data not shown).

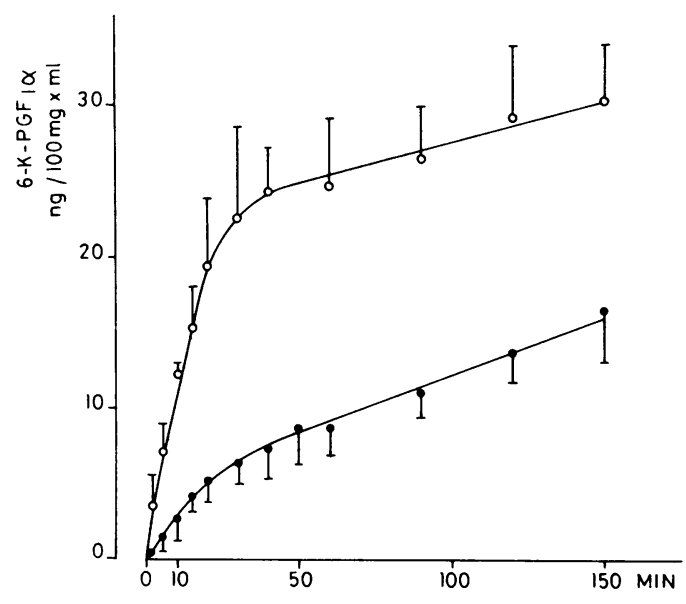

Figure 1. Kinetics of 6-K-PGF ${ }_{1 \alpha}$ release from intact and deendothelialized rabbit aorta strips. Rings of rabbit aorta were incubated for three 30 -min periods, after which all the rings were opened by a longitudinal incision. The intimal surface of half the resulting strips was scraped with a scalpel. Intact ( $\bullet$ ) and scraped (0) strips were then incubated for $150 \mathrm{~min}$. Aliquots of incubation medium were collected at various times. The results represent the accumulation of 6-K-PGF ${ }_{1 \alpha}$ in the incubation medium (mean \pm SD of quadruplicate determinations in two separate experiments). 


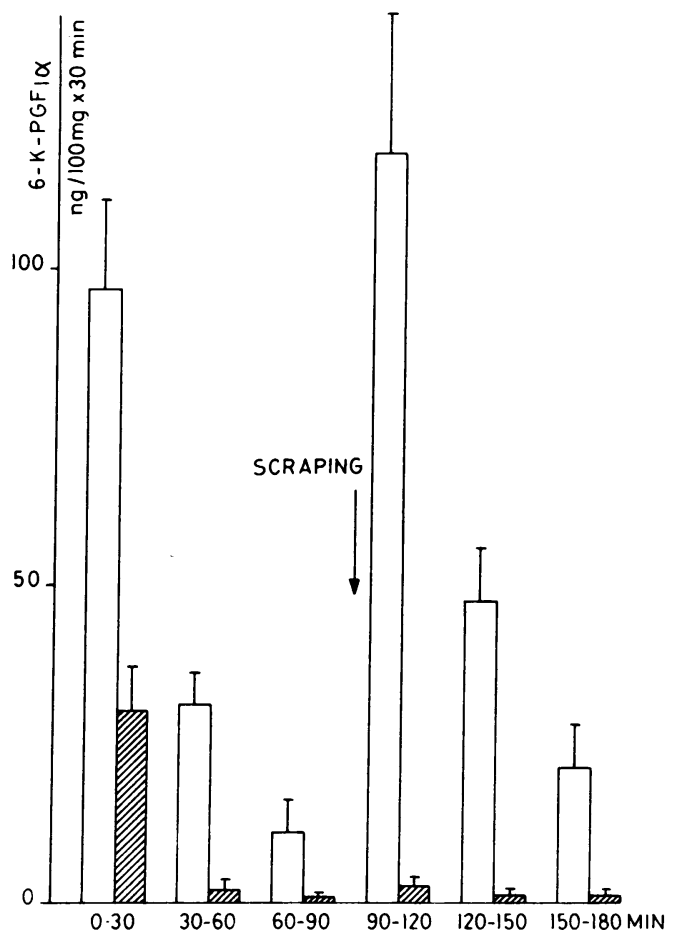

Figure 2. Inhibition by indomethacin of 6-K-PGF ${ }_{1 \alpha}$ release from the deendothelialized rabbit aorta. The aortic strips were incubated for six 30 -min periods with $(\square)$ or without $(\square)$ indomethacin $(10 \mu \mathrm{g} / \mathrm{ml})$. At the end of each period, the medium was collected and replaced. At the end of the third period, the intimal surface of all the strips was scraped with a scalpel before the incubation was resumed. Results represent the mean $\pm \mathrm{SD}$ of six determinations in two separate experiments.

Previous experiments had shown that rubbing the luminal surface abolished the stimulatory effects of acetylcholine (19) and ADP or ATP (20) on $\mathrm{PGI}_{2}$ production by the rabbit aorta. As shown on Figs. 3 and 4, the responses to ionophore A23187 and arachidonic acid were also lost in strips of deendothelialized aorta obtained either by rubbing or by scraping. The 30 -fold stimulation of 6-K-PGF 1 $_{\alpha \alpha}$ output by ionophore A23187 (5 $\mu \mathrm{M})$ in the intact rabbit aorta was reduced to 1.3 -fold in deendothelialized strips (mean of eight experiments). Continuous exposure of intact strips to arachidonic acid produced an increase of 6-K-PGF $F_{1 \alpha}$ output, which was maximal at the beginning and progressively declined. The deendothelialized aorta was unresponsive to arachidonic acid from the start to the end of the incubation (Fig. 4). Intact strips of rabbit aorta converted exogenous $\left[{ }^{3} \mathrm{H}\right]$ arachidonic acid mainly into 6-K$\mathrm{PGF}_{1 \alpha}$, and to a smaller extent into $\mathrm{PGE}_{2}, \mathrm{PGF}_{2 \alpha}$, and a compound coeluting with 12-hydroxyeicosatetraenoic acid (Fig. 5). Deendothelialized strips of aorta failed to metabolize exogenous arachidonic acid, although, as expected, they released larger amounts of endogenous 6-K-PGF ${ }_{1 \alpha}$ than the intact ones (Fig. 5). When only half of the luminal surface of the aorta strips was scraped, the initial stimulation of $6-\mathrm{K}-\mathrm{PGF}_{1 \alpha}$ release was equal to that in completely denuded strips, whereas the response to ionophore A23187 was partially maintained, roughly in proportion to the amount of residual endothelium (38\% of the response in intact strips, mean of three experiments) (data not shown). The template procedure (10) was used to

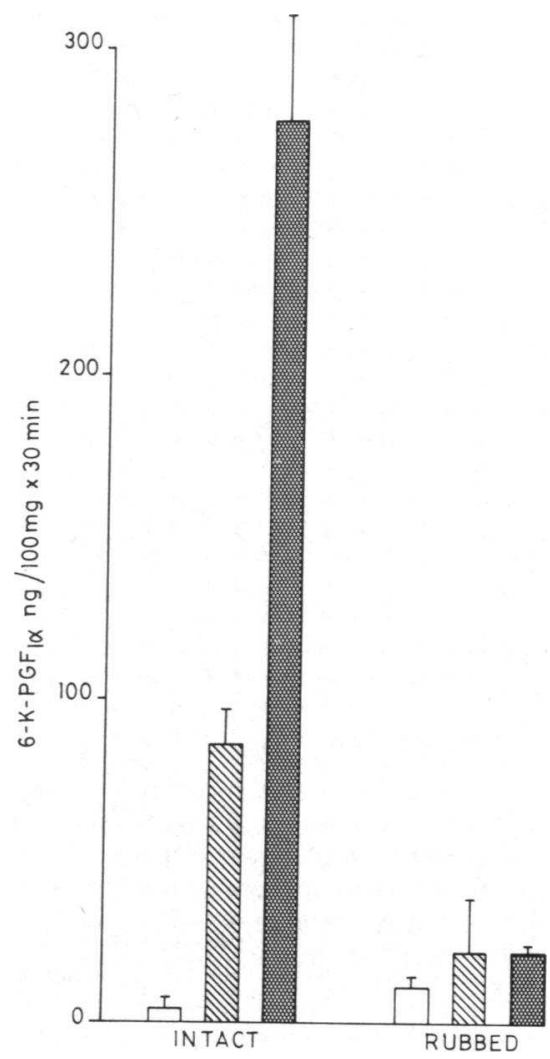

Figure 3. Unresponsiveness of 6-K-PGF ${ }_{1 \alpha}$ production from the deendothelialized rabbit aorta to ionophore A23187 and arachidonic acid. Strips of rabbit aorta, intact or rubbed against fitter paper, were incubated for five 30-min periods. Ionophore A23187 (5 $\mu \mathrm{M}$; $₫$ ) and arachidonic acid $(1 \mu \mathrm{g} / \mathrm{ml} ; \square)$ were added at the beginning of the last period. Results express the release of 6-K-PGF ${ }_{1 \alpha}$ during this period (mean \pm SD of triplicate determinations in one representative experiment). (), Control.

determine the effect of endothelium removal specifically on the release of $\mathrm{PGI}_{2}$ at the luminal surface of the aorta. As shown on Fig. 6, deendothelialization increased the luminal release of $6-\mathrm{K}-\mathrm{PGF}_{1 \alpha}$ and abolished the responsiveness to ionophore A23187.

Endothelium removal from the rabbit aorta induced the mobilization of free arachidonic acid, measured by its release into the albumin-containing incubation medium (Fig. 7). Arachidonate release (nanomoles per $100 \mathrm{mg}$ and per $30 \mathrm{~min}$ ) was maximal during the first incubation period: $6.1 \pm 2.1$ in scraped aorta strips compared with $1.7 \pm 0.5$ in the intact ones (mean $\pm S D$; five experiments). During the next $90 \mathrm{~min}$, arachidonic acid was mobilized at a lower rate, which was 3.5fold higher in the scraped strips than in the intact ones $(P=0.04)$. This rate of release did not decrease significantly during this period $(P=0.12)$. Ionophore A23187 increased the release of free arachidonic acid in the intact aorta. This effect was lost after endothelium removal (Fig. 7).

Further experiments were performed to explain the discrepancy between the progressive decline of 6-K-PGF ${ }_{1 \alpha}$ output (Figs. 1 and 4) and the continuous release of arachidonic acid (Fig. 7), observed between 30 and $120 \mathrm{~min}$ in the deendothelialized aorta. Addition of pure $\mathrm{PGH}_{2}$ synthase, in the absence of exogenous arachidonic acid, increased dose dependently the 

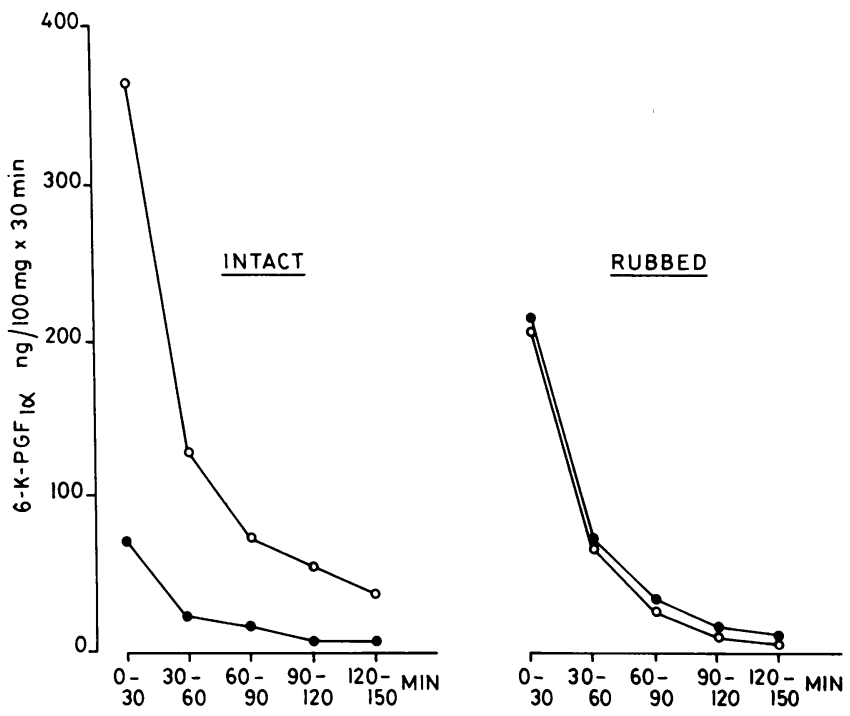

Figure 4. Comparative kinetics of 6-K-PGF ${ }_{1 \alpha}$ release by intact and deendothelialized rabbit aorta, continuously exposed to arachidonic acid. Strips of rabbit aorta, intact or rubbed against filter paper, were incubated for five 30-min periods. The medium was collected and replaced at the end of each period. Results are expressed as the mean of duplicate determinations in one representative experiment out of three. (๑), Control; (0), arachidonic acid $(5 \mu \mathrm{g} / \mathrm{ml})$ added at the beginning of each period.

release of 6-K-PGF ${ }_{1 \alpha}$ from scraped aorta strips but had almost no effect on the intact aorta (Fig. 8). Purification of samples by RPHPLC before RIA demonstrated that the immunoreactivity measured was due to authentic $6-\mathrm{K}-\mathrm{PGF}_{1 \alpha}$ and not to the cross-reaction of $\mathrm{PGE}_{2}$ or other products of the nonenzymatic breakdown of the endoperoxides generated by $\mathrm{PGH}_{2}$ synthase (data not shown). A transient inhibition of cycloox-

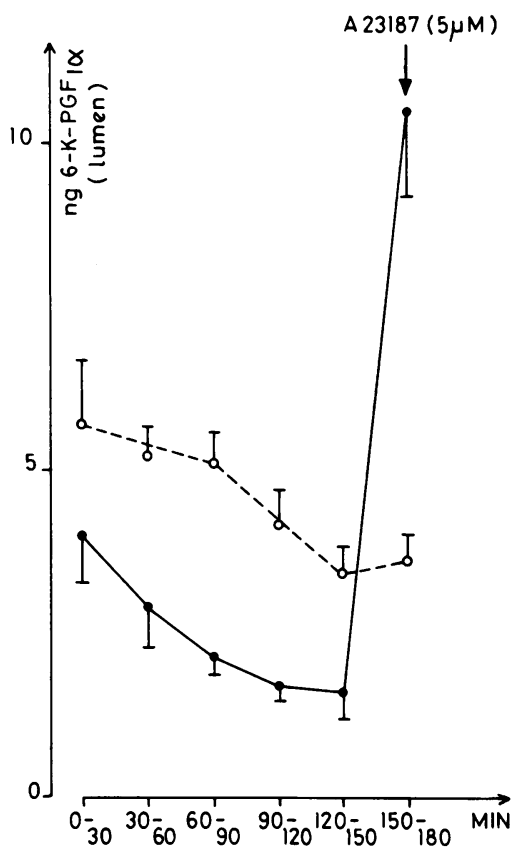

Figure 6. Kinetics of 6-K-PGF $1 \alpha$ release at the luminal surface of intact $(\bullet)$ and deendothelialized $(0)$ rabbit aorta strips. The luminal surface of aortic strips, intact or deendothelialized by scraping with a scalpel, was exposed at the bottom of incubation chambers (5-mm diam holes in a plexiglass plate) containing $0.3 \mathrm{ml}$ medium. The incubation was performed at $37^{\circ} \mathrm{C}$ for six 30 -min periods. The medium was collected and replaced at the end of each period. Ionophore A23187 was present during the last period. Results represent the mean $\pm \mathrm{SD}$ of six determinations, in two separate experiments.

ygenase by ibuprofen resulted in a rebound of $6-\mathrm{K}-\mathrm{PGF}_{1 \alpha}$ output after ibuprofen withdrawal (Fig. 9): the $90 \%$ inhibition during the $90 \mathrm{~min}$ in the presence of ibuprofen was followed

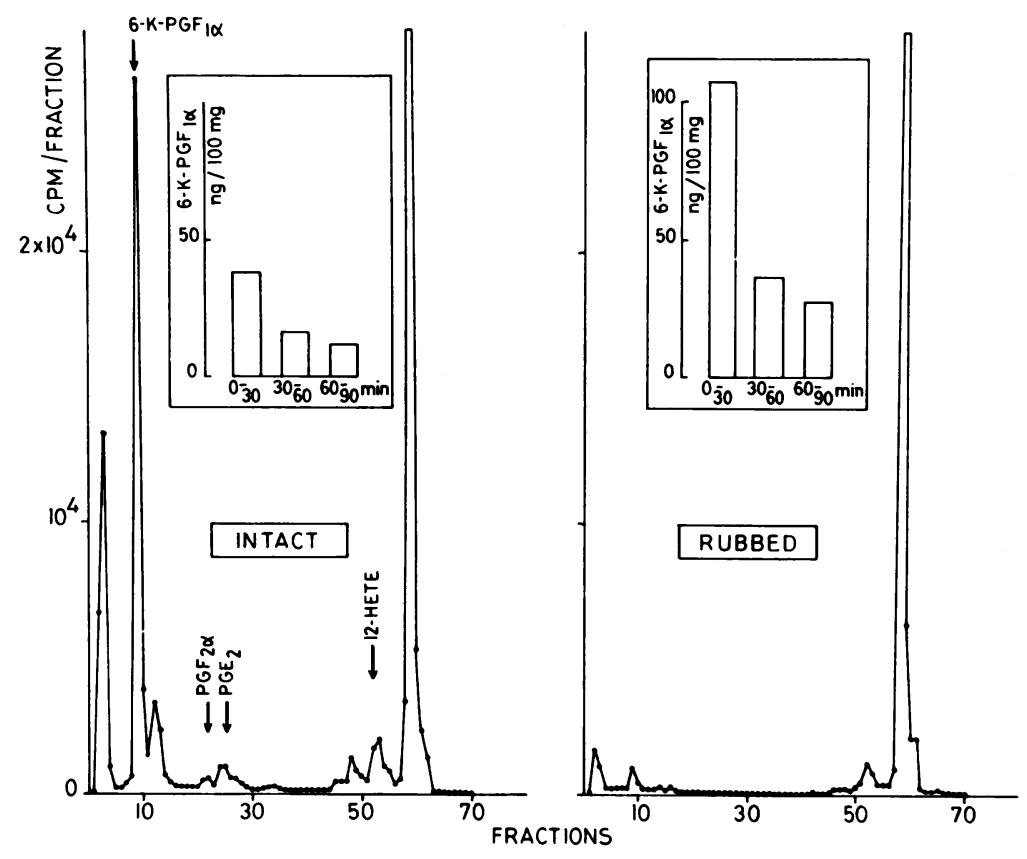

Figure 5. RPHPLC separation of the products formed from $\left[{ }^{3} \mathrm{H}\right]$ arachidonic acid by the intact and deendothelialized aorta. Strips of rabbit aorta, intact or rubbed against filter paper, were incubated for four 30 -min periods. The medium was collected and replaced at the end of each period. $\left[{ }^{3} \mathrm{H}\right]$ Arachidonic acid $(2 \mu \mathrm{Ci}, 0.5 \mu \mathrm{g})$ was added at the beginning of the fourth period. 6-K-PGF ${ }_{1 \alpha}$ was measured by RIA in the media from the initial incubations (insets), whereas the medium collected at the end of the last period was analyzed by RPHPLC, as described in Methods. The arrows indicate the retention times of various standards. The figure shows representative results, which have been obtained in duplicate in two separate experiments. 12-HETE, 12-hydroxyeicosatetraenoic acid. 


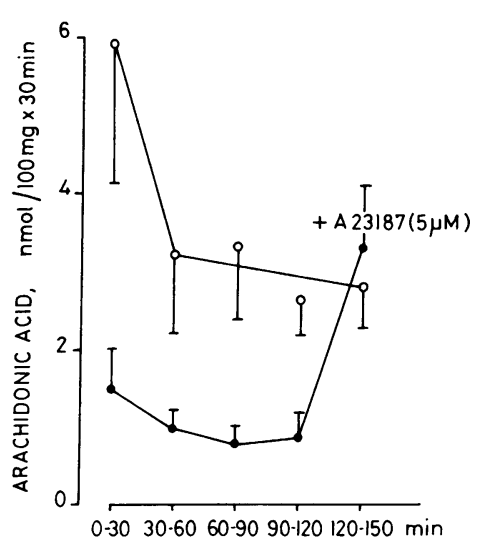

by a threefold enhancement during the next $120 \mathrm{~min}(P$ $=0.004)$. A similar rebound was observed when scraped aorta strips were incubated for $90 \mathrm{~min}$ at $0^{\circ} \mathrm{C}$ and then for $60 \mathrm{~min}$ at $37^{\circ} \mathrm{C}$ : a $61 \%$ inhibition followed by a threefold increase, by reference to scraped strips continuously incubated at $37^{\circ} \mathrm{C}$ (data not shown). BW-755C has a dual effect on prostaglandin synthase in acellular systems, stimulation at low concentrations, and inhibition at high concentrations. The stimulatory effect has been explained by the ability of BW-755C to scavenge radicals that are generated by the hydroperoxidase component
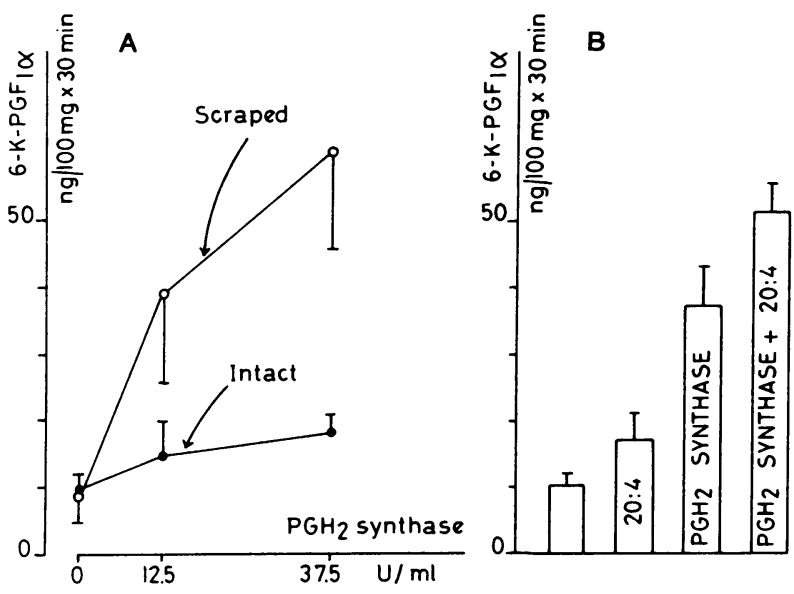

Figure 8. Stimulation of 6-K-PGF ${ }_{1 \alpha}$ release from the deendothelialized rabbit aorta by exogenous $\mathrm{PGH}_{2}$ synthase. Aortic strips, intact $(\bullet)$ or deendothelialized $(0)$ by scraping with a scalpel, were incubated for five 30 -min periods. The incubation medium was replaced at the end of each period. At the start of the last period, $\mathrm{PGH}_{2}$ synthase $(12.5$ or $37.5 \mathrm{U} / \mathrm{ml})$ and arachidonic acid $(20: 4,2 \mu \mathrm{g} / \mathrm{ml})$ were added as indicated. In the experiments depicted in $B$, all the strips were deendothelialized, and the concentration of $\mathrm{PGH}_{2}$ synthase was $12.5 \mathrm{U} / \mathrm{ml}$. Negligible amounts of material reactive with the anti-6-K-PGF ${ }_{1 \alpha}$ antibody were generated during an incubation of $\mathrm{PGH}_{2}$ synthase with arachidonic acid, in the absence of tissue. Results represent the mean \pm SD of six determinations in three separate experiments $(A)$ and six determinations in two separate experiments $(B)$.

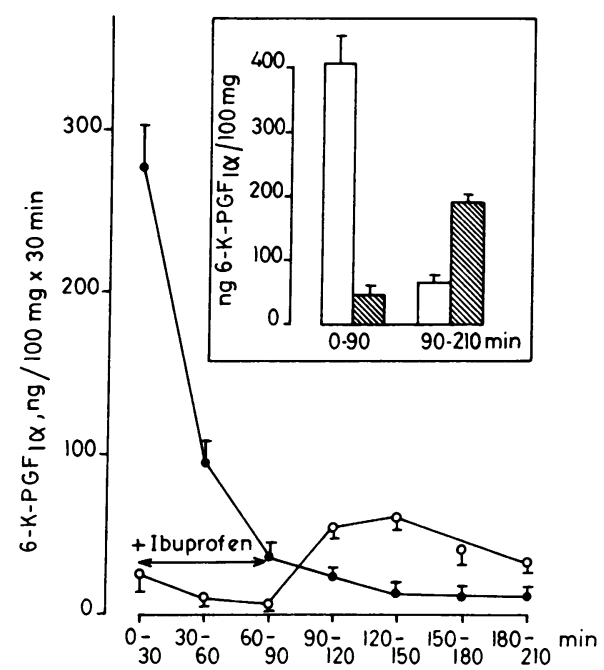

Figure 9. Kinetics of 6-K-PGF $1 \alpha$ release by deendothelialized rabbit aorta strips: effect of a transient exposure to ibuprofen. Immediately after its removal, the aorta was divided into two equal portions, one of which was immersed and manipulated in a medium containing ibuprofen $(250 \mu \mathrm{M})$. After scraping the luminal surface with a scalpel, the strips were incubated for seven 30 -min periods. The incubation medium was collected and replaced at the end of each period. Results are the mean \pm SD of quadruplicate determinations in two separate experiments. (๑), Control, without ibuprofen; (0), ibuprofen $(250 \mu \mathrm{M})$ present during the manipulation of the tissue and during the three initial periods of incubation. The inset represents the cumulated release of 6-K-PGF $F_{1 \alpha}$ during the three initial and four final periods of incubation, respectively. ( $\square)$, Control; (ه), ibuprofen (250 $\mu \mathrm{M})$ present during the three initial periods.

of prostaglandin synthase and that inactivate the cyclooxygenase (21). BW-755C prolonged the release of $6-\mathrm{K}_{-} \mathrm{PGF}_{1 \alpha}$ by the deendothelialized rabbit aorta (Fig. 10). $3 \mu \mathrm{M}$ of BW-755C caused a negligible inhibition of 6-K-PGF ${ }_{1 \alpha}$ output during its 60-min exposure to the scraped aorta strips, followed by a doubling of $6-\mathrm{K}-\mathrm{PGF}_{1 \alpha}$ release during the $90 \mathrm{~min}$ after the removal of the drug. $10 \mu \mathrm{M}$ of $\mathrm{BW}-755 \mathrm{C}$ produced a $34 \%$ inhibition followed by a 2.7-fold stimulation. This stimulatory effect of BW-755C was highly significant $(P=0.002)$. Other antioxidants reported to protect the synthesis of $\mathbf{P G I}_{2}$, ascorbic acid (22), and nafazatrom (23) did not modify the kinetics of 6-K-PGF ${ }_{1 \alpha}$ release from the deendothelialized aorta (data not shown).

\section{Discussion}

Our results indicate that the removal of the aortic endothelium induced a sustained mobilization of free arachidonic acid, a transient stimulation of $\mathbf{P G I}_{2}$ synthesis, and an increased release of $\mathrm{PGI}_{2}$ at the luminal surface, accompanied and followed by a complete unresponsiveness to all the stimuli that increase $\mathrm{PGI}_{2}$ in the intact aorta, including arachidonic acid itself. Since we checked carefully to see that the endothelium was completely removed by the mechanical procedures used, it is most likely that the events measured in this study occurred in the smooth muscle cells. Increased $\mathrm{PGI}_{2}$ synthesis 


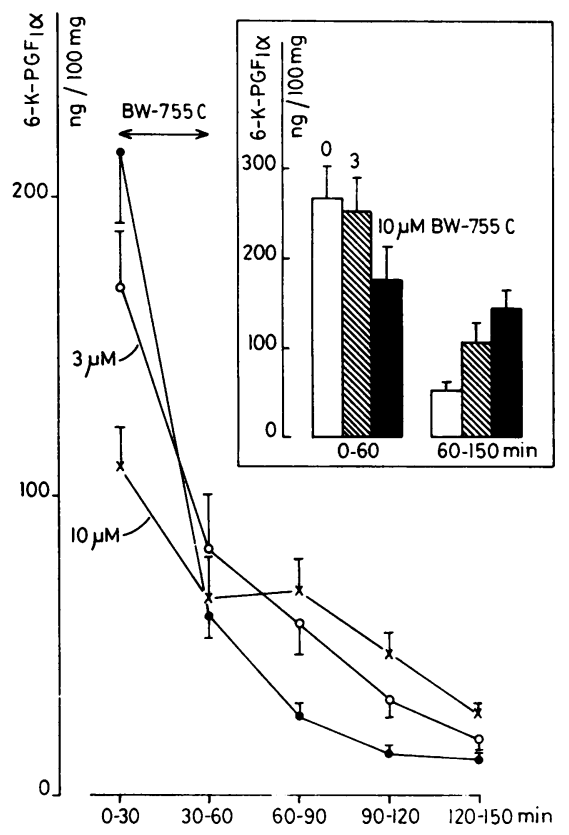

Figure 10. Effect of BW-755C on the release of 6-K-PGF ${ }_{1 \alpha}$ by the deendothelialized rabbit aorta. Strips of rabbit aorta, deendothelialized by scraping with a scalpel, were incubated for five 30-min periods. The medium was collected and replaced at the end of each period. Results are the mean \pm SD of eight determinations, in four

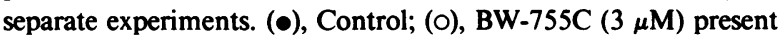
during the two initial periods; $(X)$, BW-755C $(10 \mu \mathrm{M})$ present during the two initial periods. The inset represents the cumulated release of 6-K-PGF ${ }_{1 \alpha}$ during the two initial and three final periods of incuba-

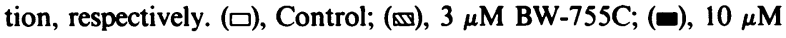
BW-755C.

after endothelium removal is likely to be the consequence of the increased availability of free arachidonic acid. This spontaneous mobilization of endogenous arachidonic acid could also explain the lack of stimulatory effect of exogenous arachidonic acid on $\mathrm{PGI}_{2}$ production (saturation of the cyclooxygenase) and the inability of ionophore A23187 to release additional free arachidonic acid. The progressive decline of $\mathrm{PGI}_{2}$ release, despite the continuous availability of free arachidonic acid, is likely to be due to cyclooxygenase inactivation, a contention supported by three arguments. The output of $\mathrm{PGE}_{2}$ was initially enhanced and decreased progressively, parallel to $\mathrm{PGI}_{2}$, but at a much lower level, thus excluding $\mathbf{P G I}_{2}$ synthase inactivation as the (only) explanation of the data. The stimulatory effect of exogenous $\mathrm{PGH}_{2}$ synthase indicates that, in the deendothelialized aorta, the limiting factor for $\mathbf{P G I}_{2}$ synthesis was indeed the cyclooxygenase activity, and confirms the availability of free arachidonic acid in this situation. Finally, the prolongation of $\mathrm{PGI}_{2}$ synthesis by a transient exposure to the reversible cyclooxygenase inhibitor ibuprofen or the radical scavenger BW-755C suggests that inactivation of cyclooxygenase might result from a suicidal oxidation by prostaglandin endoperoxides.

Whether smooth muscle cells contribute significantly to the production of $\mathrm{PGI}_{2}$ by arteries remains a controversial issue. Studies performed with cultured aortic smooth muscle cells have not provided conclusive answers. $\mathrm{PGI}_{2}$ is the major eicosanoid produced by cells from rat, rabbit, and bovine aorta (1-6), whereas $\mathrm{PGE}_{2}$ and $\mathrm{PGF}_{2 \alpha}$ are the main products formed in cells cultured from porcine aorta (7-9). Aortic smooth muscle cells dedifferentiate in culture and lose some of their native properties, such as contractility (24). Our observation that, after complete removal of the endothelium, the aorta was able to produce large amounts of $\mathrm{PGI}_{2}$, but less than the intact aorta stimulated by arachidonic acid and only for a short period (Fig. 4), is perfectly consistent with the recent study of De Witt et al. (13) who have shown that the aortic smooth muscle cells contain as much $\mathrm{PGI}_{2}$ synthase as, but 20 times less cyclooxygenase than the aortic endothelial cells. Our data are also consistent with the observation by Hornstra et al. (25) that disruption of the endothelium results in the increased release of a heat-labile inhibitor of platelet aggregation by the rat and the rabbit aorta, and with the results of Goldsmith (26) who showed that the release of $\mathrm{PGI}_{2}$ at the luminal surface of the bovine aorta was initially increased after in vitro removal of the endothelium. On the contrary, De Mey et al. (11) have concluded, from the inability of deendothelialized strips of canine femoral arteries to convert exogenous $\left[{ }^{14} \mathrm{C}\right]$ arachidonic acid into $6-\mathrm{K}-\mathrm{PGF}_{1 \alpha}$, that the endothelium is the key site of $\mathrm{PGI}_{2}$ synthesis in the arterial wall. We have made the same observation in the deendothelialized rabbit aorta (Fig. 5), but the simultaneous measurement of the endogenous production of 6-K-PGF ${ }_{1 \alpha}$ leads us to an opposite conclusion. The deendothelialized aorta released more $\mathrm{PGI}_{2}$ than the intact one, and the lack of conversion of exogenous radiolabeled arachidonic acid may be the consequence of isotopic dilution by the large amounts of endogenous free arachidonic acid mobilized after endothelium removal. This underscores the danger of using the conversion of exogenous arachidonic acid as the only method to evaluate eicosanoid biosynthetic capacity. This is true also for the work of Eldor et al. (10) who have shown that removal of the endothelium from the rabbit aorta in vivo abolishes the conversion of exogenous arachidonic acid into $\mathrm{PGI}_{2}$ measured at the luminal surface. These authors did not report an increase of the spontaneous release of $\mathrm{PGI}_{2}$ after endothelium removal. Since the stimulation observed in our study was transient, it might have been missed in the time interval between the deendothelialization performed in vivo and the start of the in vitro incubation.

The short-lived release of $\mathrm{PGI}_{2}$, in spite of a continuous mobilization of endogenous free arachidonic acid, that we have observed in the deendothelialized rabbit aorta is similar to the transient production of $\mathrm{PGI}_{2}$ by the intact rabbit aorta continuously perfused with exogenous arachidonic acid (27) and to the observation that cultured endothelial cells respond to arachidonic acid only once $(6,28)$. In each case, the rapid decline of $\mathrm{PGI}_{2}$ production is likely to be due to self-inactivation of the cyclooxygenase, involving the irreversible oxidation of the enzyme by a free radical generated during the reduction of prostaglandin $\mathrm{G}_{2}$ into prostaglandin $\mathrm{H}_{2}(21,27,28)$. Our results suggest that $\mathrm{BW}-755 \mathrm{C}$, which, depending on the concentration, stimulates or inhibits cyclooxygenase in a cell-free preparation (21), constitutes the model of a specific drug protecting against this inactivation in vascular smooth muscle 
cells. Indeed a concentration of $\mathrm{BW}-755 \mathrm{C}$ as low as $3 \mu \mathrm{M}$ prolongs the release of $\mathrm{PGI}_{2}$ by the deendothelialized aorta.

Mechanical removal of the endothelium seems to represent a straightforward method to evaluate its contribution to phenomena occurring in arteries. In particular, this procedure has been used to demonstrate that acetylcholine and other agents relax the rabbit aorta and other arteries by acting on endothelial cells $(29,30)$. Our study indicates that experiments involving endothelium removal should be interpreted with great caution, since this procedure dramatically alters the metabolism of arachidonic acid in the subendothelial layer. Other acute biochemical modifications after endothelium removal have been noticed in the aorta, including increased cyclic GMP content (31) and phosphorylation of one specific protein (32).

One question raised by our observations is whether the mobilization of arachidonic acid and the resulting $\mathrm{PGI}_{2}$ synthesis after endothelium removal is a mere consequence of the trauma imposed to the aortic smooth muscle or is due to the disruption of endothelial-smooth muscle cell interactions. Control and deendothelialized samples were submitted to the same trauma when the aorta was cut into rings. This trauma, followed by recovery, might be responsible for the initial and transient phase of free arachidonic acid release. It could be speculated that the sustained release observed in the deendothelialized aorta results from the permanent loss of some endothelium-smooth muscle interaction, of which several examples have been described (33-36), but additional studies are required to support this hypothesis. Whatever the mechanism involved, our study suggests that the local release of $\mathrm{PGI}_{2}$ induced by endothelial lesions might contribute to the increased systemic production of $\mathrm{PGI}_{2}$ observed in patients with atherosclerosis (37).

\section{Acknowledgments}

We thank Dr. R. Pochet for his help in the microscopic examinations, Dr. V. de Maertelaer for performing the statistical analysis, Mr. D. Martins for designing the template device, and Mrs. D. Leemans for typing the manuscript. We are grateful to Dr. J. E. Dumont for his continuous interest and support.

This work was performed under contract of the Ministère de la Politique Scientifique (Action Concertée).

\section{References}

1. Whiting, J., K. Salata, and J. M. Bailey. 1980. Aspirin: an unexpected side effect on prostacyclin synthesis in cultured vascular smooth muscle cells. Science (Wash. DC). 210:663-665.

2. Larrue, J., M. Rigaud, D. Daret, J. Demond, J. Durand, and H. Bricaud. 1980. Prostacyclin production by cultured smooth muscle cells from atherosclerotic rabbit aorta. Nature (Lond.). 285:480-483.

3. Larrue, J., B. Dorian, J. Demond-Henri, and H. Bricaud. 1981. Endogenous arachidonic acid metabolism by cultured arterial smooth muscle cells. Biochem. Biophys. Res. Commun. 101:861-867.

4. Ingerman-Wojenski, C., M. J. Silver, J. B. Smith, and E. Macarak. 1981. Bovine endothelial cells in culture produce thromboxane as well as prostacyclin. J. Clin. Invest. 67:1292-1296.

5. Coughlin, S. R., M. A. Moskowitz, H. N. Antoniades, and L. Levine. 1981. Serotonin receptor-mediated stimulation of bovine smooth muscle cell prostacyclin synthesis and its modulation by plateletderived growth factor. Proc. Natl. Acad. Sci. USA. 78:7134-7138.
6. Dejana, E., G. Balconi, C. De Castellarnau, B. Barbieri, M. Vergara-Dauden, and G. De Gaetano. 1983. Prostacyclin production by human endothelial and bovine smooth muscle cells in culture. Effect of repeated stimulation with arachidonic acid, thrombin and ionophore A23187. Biochim. Biophys. Acta. 750:261-267.

7. MacIntyre, D. E., J. D. Pearson, and J. L. Gordon. 1978. Localisation and stimulation of prostacyclin production in vascular wall. Nature (Lond.). 271:549-551.

8. Siess, W., F. Dray, C. C. Seillan, C. Ody, and F. Russo-Marie. 1981. Prostanoid synthesis by vascular slices and cultured vascular cells of piglet aorta. Biochem. Biophys. Res. Commun. 99:608-616.

9. Ody, C., C. Seillan, and F. Russo-Marie. 1982. 6-K-PGF ${ }_{1 \alpha}$, $\mathrm{PGE}_{2}, \mathrm{PGF}_{2}$ and $\mathrm{TxB}_{2}$ production by endothelial cells, smooth muscle cells and fibroblasts cultured from piglet aorta. Biochem. Biophys. Acta. 712:103-110.

10. Eldor, A., D. J. Falcone, D. P. Hajjar, C. R. Minick, and B. B. Weksler. 1981. Recovery of prostacyclin production by de-endothelialized rabbit aorta. J. Clin. Invest. 67:735-741.

11. De Mey, J. G., M. Claeys, and P. M. Van Houtte. 1982. Endothelium-dependent inhibitory effects of acetylcholine, ATP, thrombin and arachidonic acid in the canine femoral artery. $J$. Pharmacol. Exp. Ther. 222:166-173.

12. Smith, W. L., D. L. De Witt, and M. L. Allen. 1983. Bimodal distribution of the $\mathrm{PGI}_{2}$ synthase antigen in smooth muscle cells. $J$. Biol. Chem. 258:5922-5926.

13. De Witt, D. L., J. S. Day, W. K. Sonnenburg, and W. L. Smith. 1983. Concentrations of prostaglandin endoperoxide synthase and prostaglandin $I_{2}$ synthase in the endothelium and smooth muscle of bovine aorta. J. Clin. Invest. 72:1882-1888.

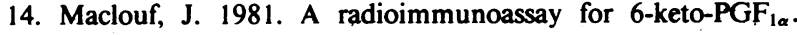
Methods Enzymol. 86:273-286.

15. Wickramasinghe, J. A. F., W. Morozowich, W. E. Hamlin, and S. R. Shaw. 1973. Detection of $\mathrm{PGF}_{2 \alpha}$ as pentafluorobenzyl ester by electron-capture GLC. J. Pharm. Sci. 62:1428-1431.

16. Poole, J. C. F., A. G. Sanders, H. W. Florey. 1958. The regeneration of aortic endothelium. J. Pathol. Bacteriol. 75:133-142.

17. Morrison, A. D., L. Orci, L. Berwick, A. Perrelet, and A. I. Winegrad. 1977. The effects of anoxia on the morphology and composite metabolism of the intact aortic intima-media preparation. J. Clin. Invest. 59:1027-1037.

18. Dixon, W. J., M. B. Brown, L. Engleman, J. W. Frane, M. A. Hill, R. I. Jennrich, and J. D. Toporek. 1981. BMDP Statistical Software. University of California Press, Berkeley, CA.

19. Boeynaems, J. M., and N. Galand. 1983. Cholinergic stimulation of vascular prostacyclin synthesis. Prostaglandins. 26:531-545.

20. Boeynaems, J. M., and N. Galand. 1983. Stimulation of vascular prostacyclin synthesis by extracellular ADP and ATP. Biochem. Biophys. Res. Commun. 112:290-296.

21. Marnett, L. J., P. H. Siedlik, and L. W, M. Fung. 1982. Oxidation of phenidone and BW-755C by prostaglandin endoperoxide synthetase. J. Biol. Chem. 257:6957-6964.

22. Beetens, J. R., M. Claeys, and A. G. Herman. 1981. Antioxidants increase the formation of $6-0 \times 0-P^{-} F_{1 \alpha}$ by ram seminal vesicle microsomes. Biochem. Pharmacol. 30:2811-2815.

23. Sevilla, M. D., P. Neta, and L. J. Marnett. 1983. Reaction of the anti-thrombotic and antimetastatic agent nafazatrom with oxidizing radicals. Biochem. Biophys. Res. Commun. 115:800-806.

24. Chamley, J. H., G. R. Campbell, J. D. McConnell, and U. Groschel-Stewart. 1977. Comparison of vascular smooth muscle cells from adult human monkey and rabbit in primary culture and subculture. Cell Tissue Res. 177:503-522.

25. Hornstra, G., E. Haddeman, and J. A. Don. 1978. Some investigations in the role of prostacyclin in thromboregulation. Thromb. Res, 12:367-374. 
26. Goldsmith, J. C. 1982. Contribution of the subendothelium to prostacyclin release after vascular injury. J. Lab. Clin. Med. 100;574584.

27. Kent, R. S., S. L. Diedrich, and A. R. Whorton. 1983. Regulation of vascular prostaglandin synthesis by metabolites of arachidonic acid in perfused rabbit aorta. J. Clin. Invest. 72:455-465.

28. Brotherton, A. F. A., and J. C. Hoak. 1983. Prostacyclin biosynthesis in cultured vascular endothelium is limited by deactivation of cyclooxygenase. J. Clin. Invest. 72:1255-1261.

29. Furchgott, R. F., and J. V. Zawadzki. 1980. The obligatory role of endothelial cells in the relaxation of arterial smooth muscle by acetylcholine. Nature (Lond.). 288:373-376.

30. Chand, N., and B. M. Altura. 1981. Acetylcholine and bradykinin relax intrapulmonary arteries by acting on endothelial cells: role in lung vascular diseases. Science (Wash. DC). 213:1376-1379.

31. Rapoport, R. M., and F. Murad. 1983. Agonist-induced endothelium-dependent relaxation in rat thoracic aorta may be mediated through cGMP. Circ. Res. 52:352-357.

32. Rapoport, R. M., M. B. Draznin, and F. Murad. 1983.
Endothelium-dependent relaxation in rat aorta may be mediated through CGMP-dependent protein phosphorylation. Nature (Lond.). 306:174-176.

33. Stetz, E. M., G. Mayno, and I. Joris. 1979. Cellular pathology of the rat aorta. Pseudo-vacuoles and myo-endothelial herniae. Virchows Arch. A Pathol. Anat. Histol. 383:135-148.

34. Castellot, J. J., M. L. Addonizio, R. Rosenberg, and M. J. Karnovsky. 1981. Cultured endothelial cells produce a heparin-like inhibitor of smooth muscle cell growth. J. Cell. Biol. 90:372-379.

35. Hajjar, D. P., D. J. Falcone, S. Fowler, and C. R. Minick. 1981. Endothelium modifies the altered metabolism of the injured aortic wall. Am. J. Pathol. 102:28-39.

36. Wight, T. N., K. D. Curwen, M. M. Litrenta, D. R. Alonso, and C. R. Minick. 1983. Effect of endothelium on glycosaminoglycan accumulation in injured rabbit aorta. Am. J. Pathol. 113:156-164.

37. Fitzgerald, G. A., B. Smith, A. K. Pedersen, and A. R. Brash. 1984. Increased prostacyclin biosynthesis in patients with severe atherosclerosis and platelet activation. N. Engl. J. Med. 310:1065-1068. 